\title{
Bio-synthetic compartments as mimics of natural organelles and celles
}

\author{
Cornelia Gabriela Palivan
}

University of Basel

Philadelphia, 2020 


\section{Bio-Synthetic assemblies}

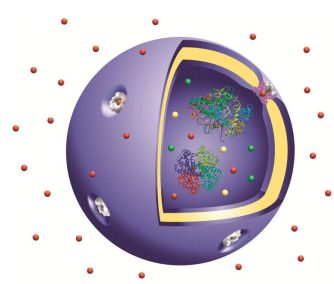

Nanoreactors, Artificial Organelles

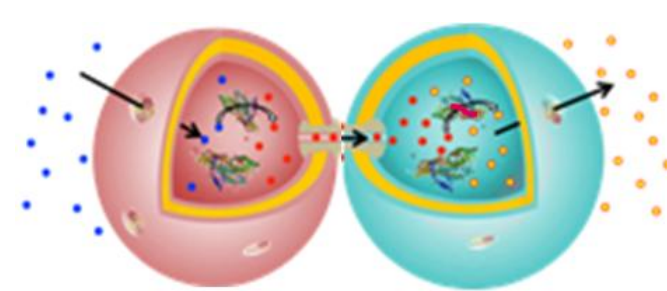

Interconnected Organelles
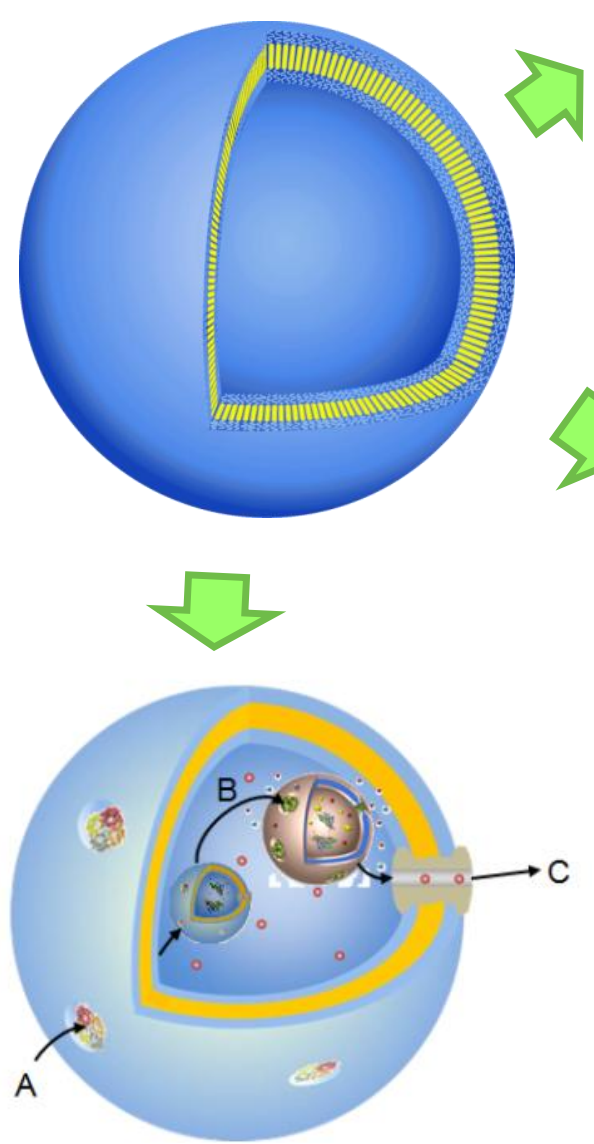

Compartments-in-compartment, artificial cells

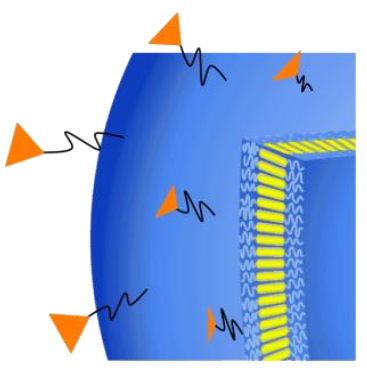

Functionalized carriers

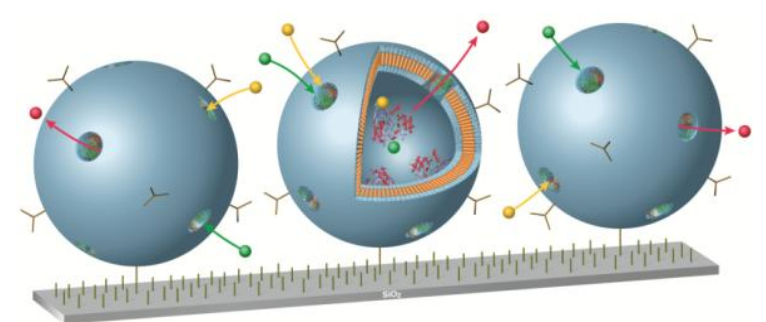

„Active" surfaces 


\section{Thickness vs properties of polymer membrane}

Polymer vesicles (polymersomes):
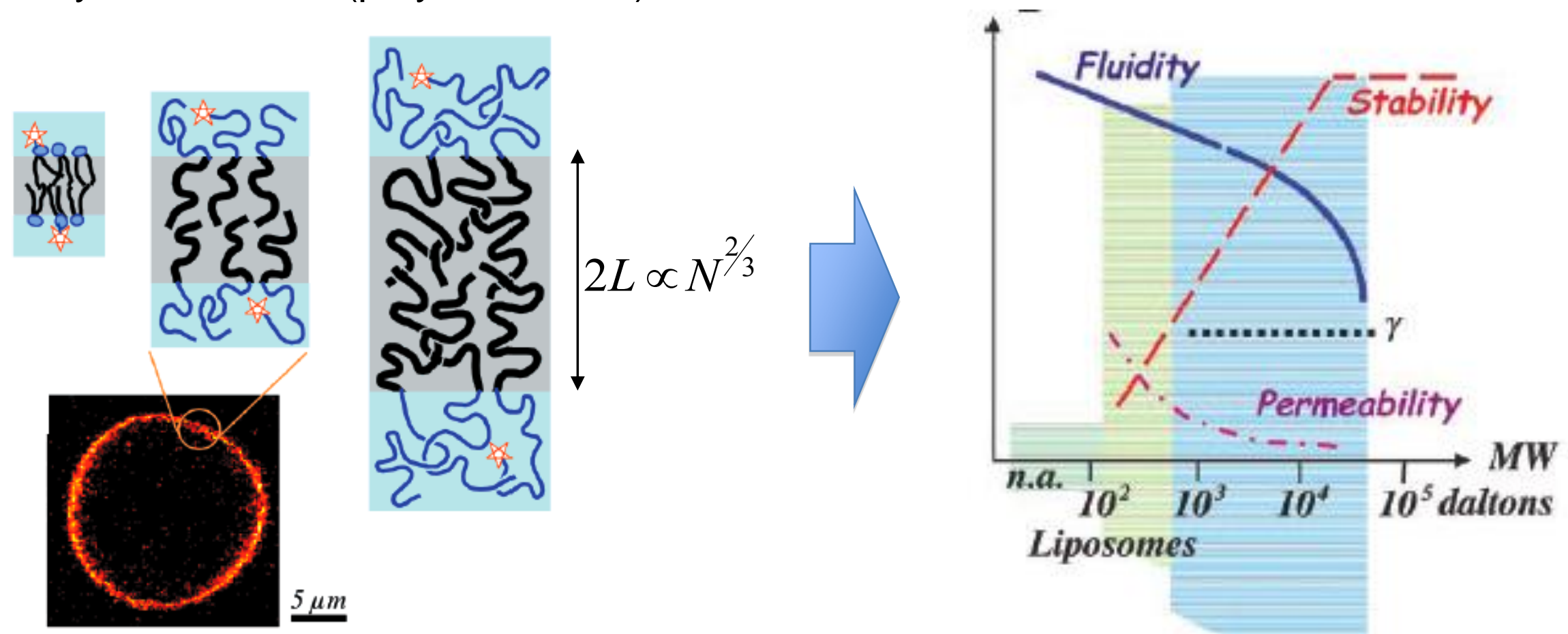

\section{Liposomes}

Polymersomes

Discher D.E. \& Eisenberg A. Science, 2002, 297, 967 


\section{Catalytic nanocompartments: Concept}

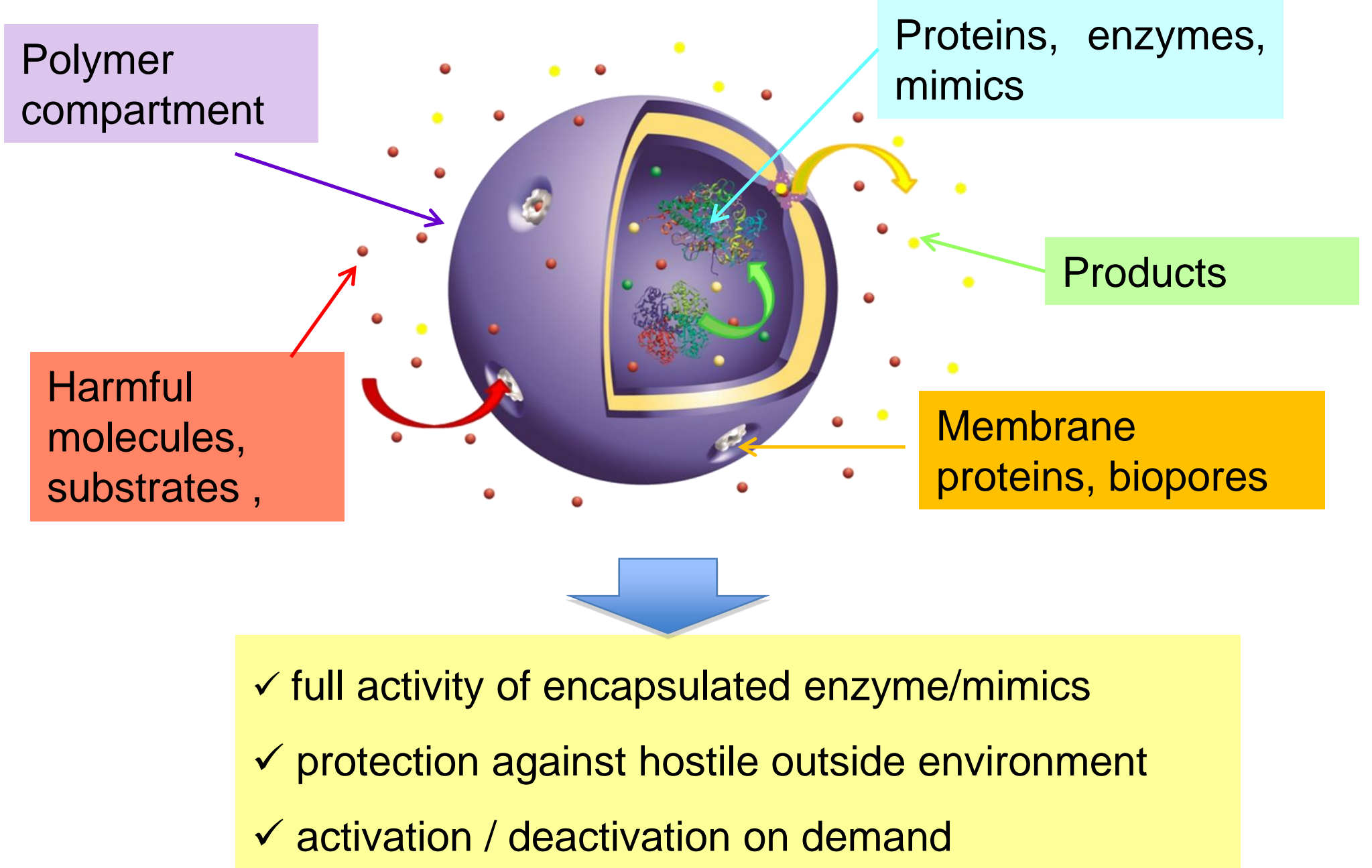

P. Tanner, S. Egli, V. Balasubramanian, O. Onaca, C. G. Palivan, W. Meier, FEBS Letter, 2011, 585, 1699.

M. Lomora, G. Gunkel-Grabole, S. Mantri, C. G. Palivan, Chem. Comm., 2017, 53, 10148.

A. Belluati, I. Craciun, J. Liu, C.G. Palivan, Biomacromolecules, 2018, DOI: 10.1021/acs.biomac.8b01019. 


\section{Polymer membrane: mimic of biomembranes}

Cell membrane

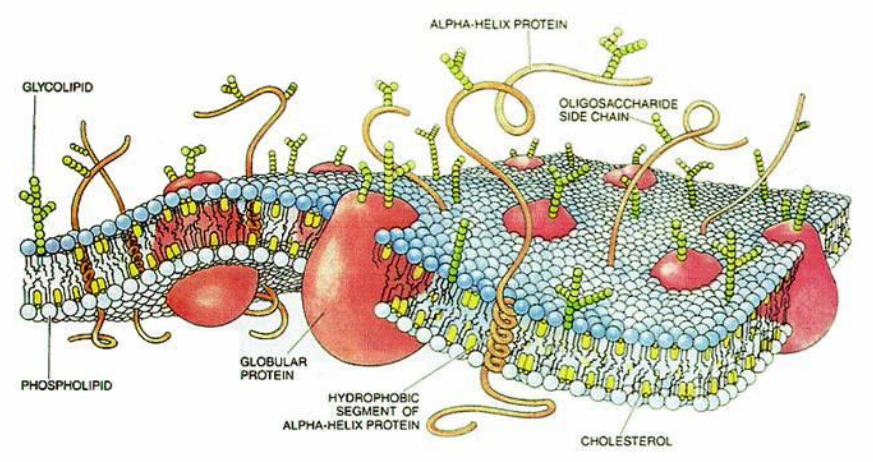

\section{Polymer membrane}

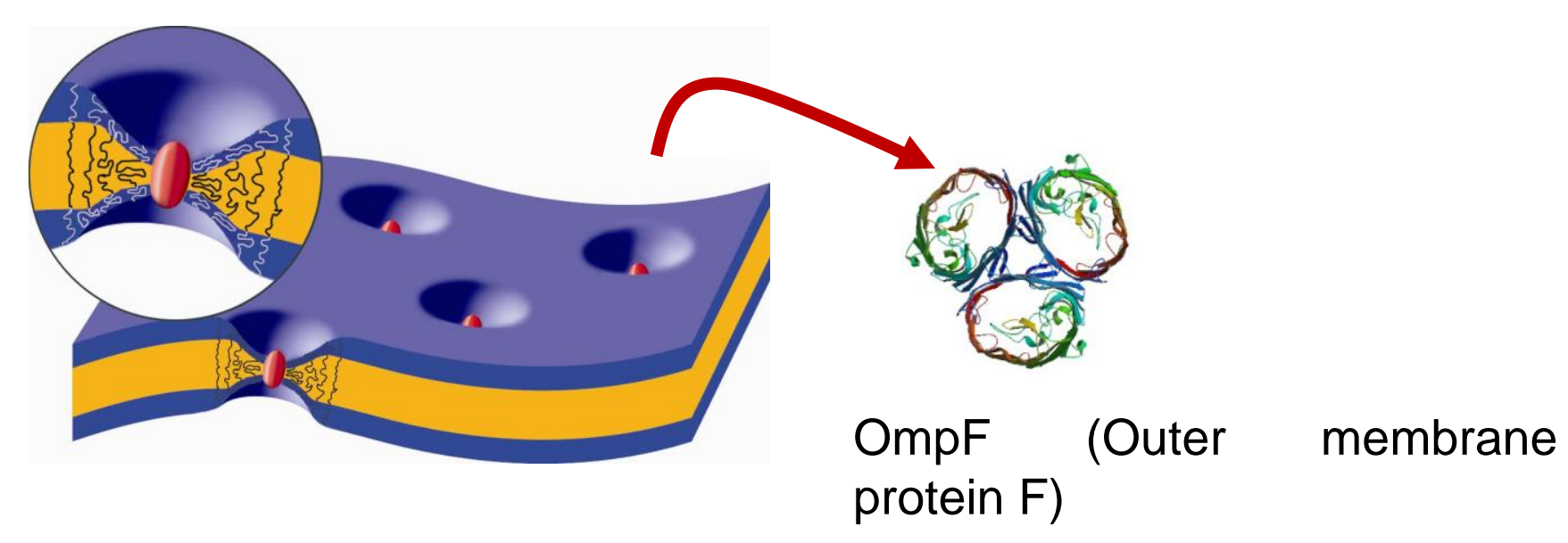

Nardin et al. Chem. Commun., 2000, 1433.

M. Garni, S. Thamboo, C. Schenenberger, C.G. Palivan, BBA-Biomembranes, 2017, 1859, 619. 
> Protein decorated membranes

$>$ Artificial organelles

$>$ Mimics of cells 


\section{Raw material: amphiphilic block copolymer}

\section{Poly-2-methyl-2-oxazoline Polydimethylsiloxane Poly-2-methyl-2-oxazoline}
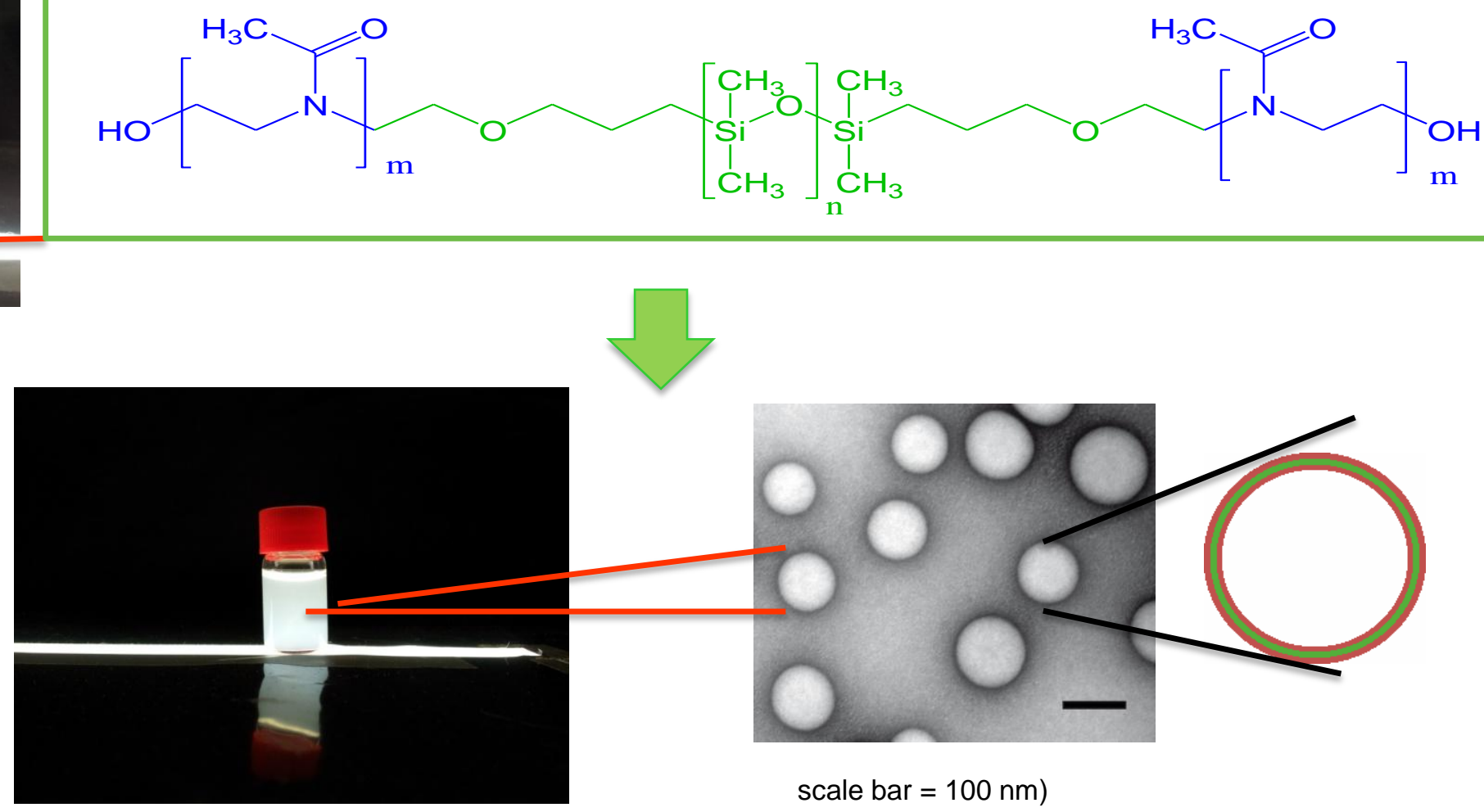

Hollow spheres: vesicles

O. Onaca, D.W. Hughes, V. Balasubramanian, M. Grzelakowski, W.

$(50 \mathrm{~nm}-1 \mu \mathrm{m})$

Meier, C. G. Palivan, Macromol. Biosci, 2010, 10(5), 531 


\section{Polymersomes engineered for ion selective permeability}
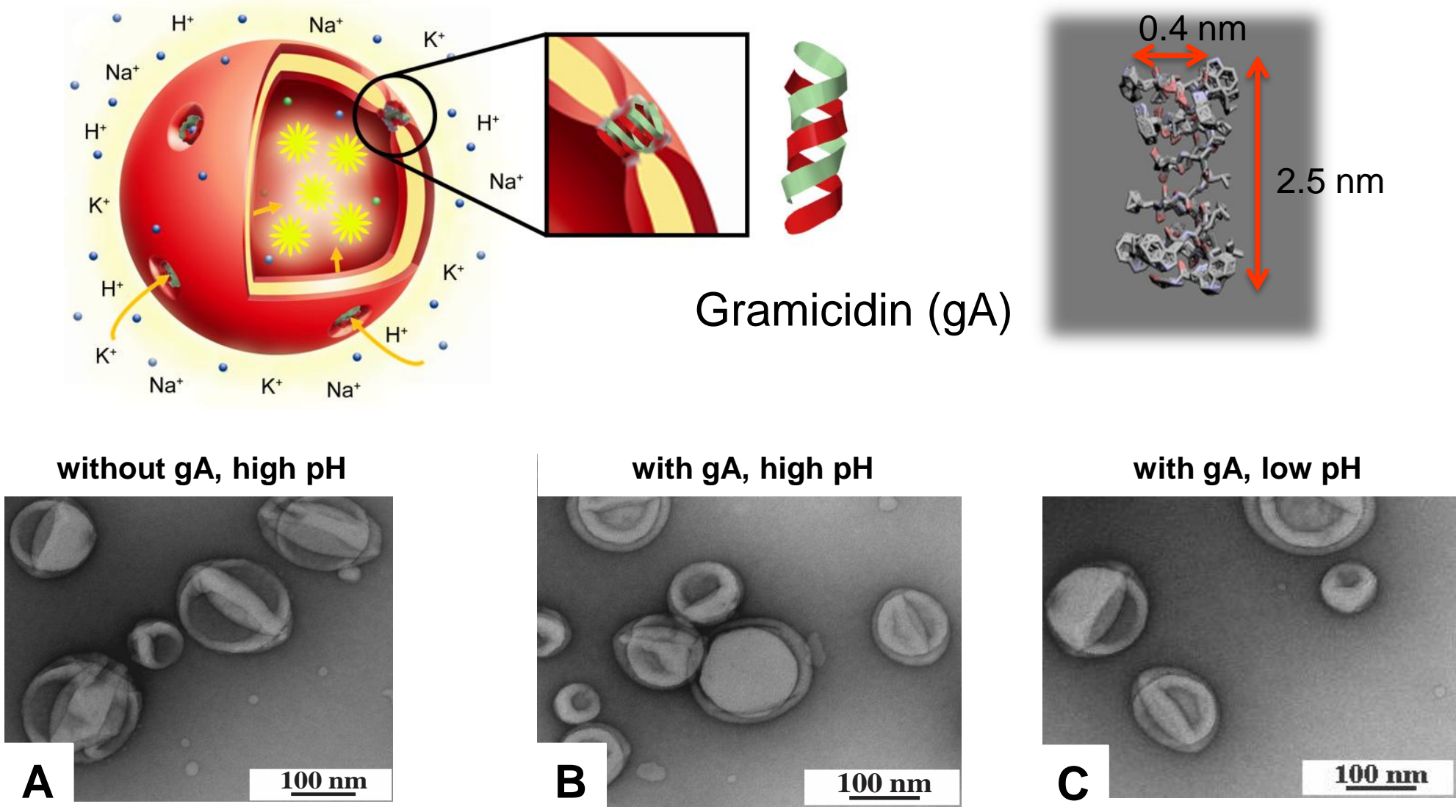

$$
\begin{aligned}
& \mathrm{Rh}=111 \mathrm{~nm} \\
& \mathrm{Rg}=104 \mathrm{~nm} \\
& \rho=\mathrm{Rg} / \mathrm{Rh}=0.91
\end{aligned}
$$

$$
\begin{aligned}
& \mathrm{Rh}=111 \mathrm{~nm} \\
& \mathrm{Rg}=102 \mathrm{~nm} \\
& \rho=\mathrm{Rg} / \mathrm{Rh}=0.91
\end{aligned}
$$




\section{Polymersomes with functional gA biopores}
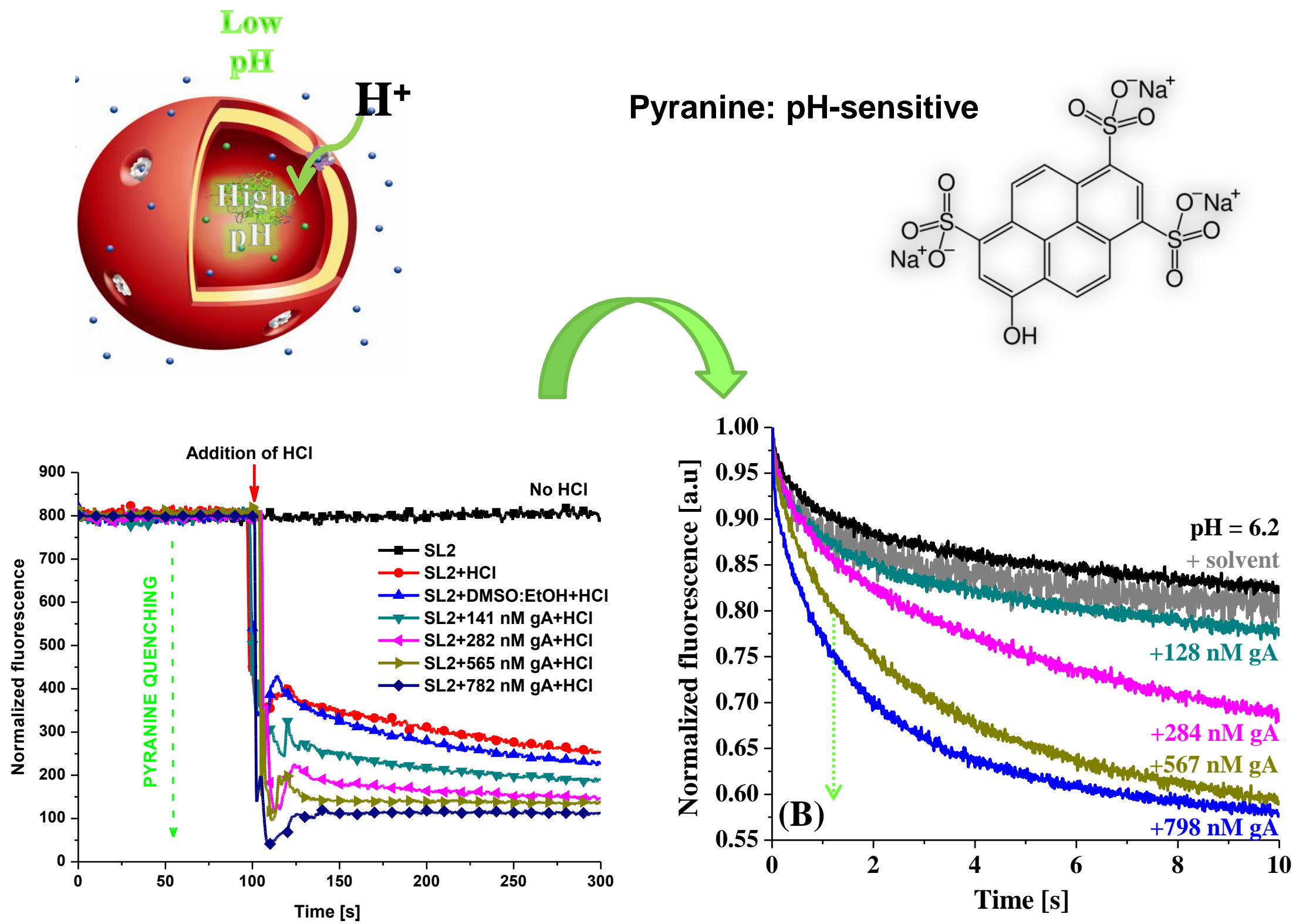


\section{Polymersomes with engineered ion selective permeability $\left(\mathrm{H}^{+}, \mathrm{Na}^{+}, \mathrm{K}^{+}\right)$}
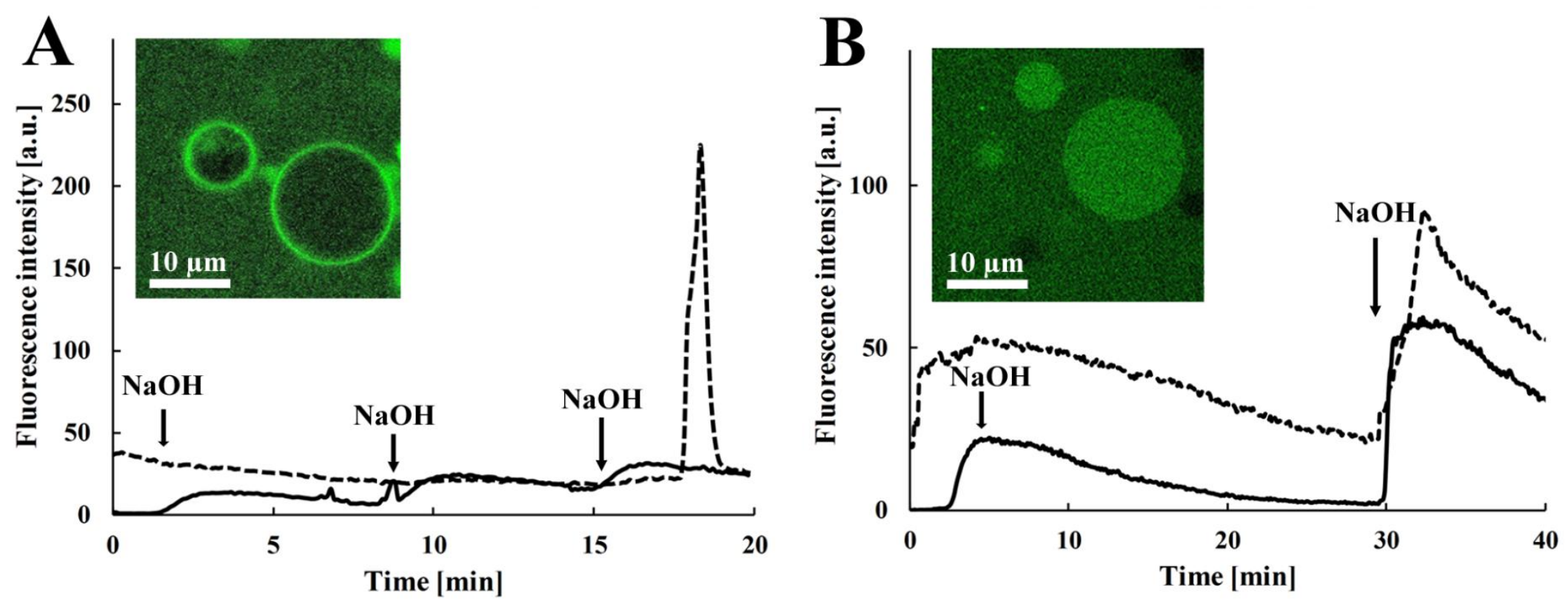

Fluorescent intensity change over time of 5(6)-carboxyfluorescein (CF) inside and outside of polymer GUVs in absence (A), and in upon insertion of gA (B). Insets: representative LSM images showing the principle of blocking the membrane to protons (A) and permeability of the membrane to protons by insertion of $\mathrm{gA}(\mathrm{B})$. Fluorescence intensity inside GUVs (dotted line), and outside GUVs (solid line).

$\checkmark$ Both polymersomes and giant vesicles with engineered ion selective permeability of the membrane (membrane thickness $9.2 \mathrm{~nm}$ ). 


\section{Membrane thickness: gA insertion ?}
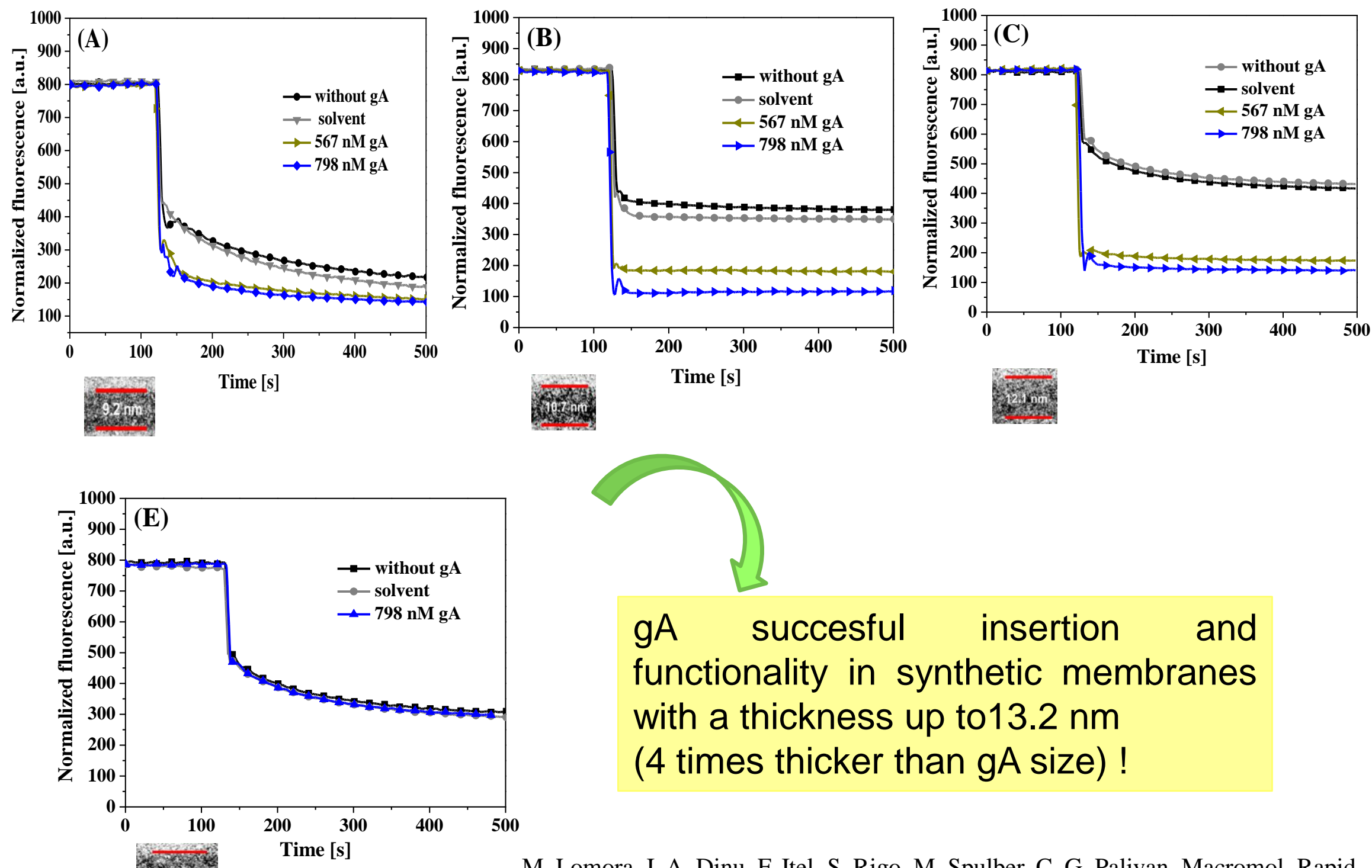

gA succesful insertion and functionality in synthetic membranes with a thickness up to13.2 nm (4 times thicker than gA size)! 
$>$ Artificial organelles

$>$ Mimics of cells 


\section{Artificial organelles: Concept}

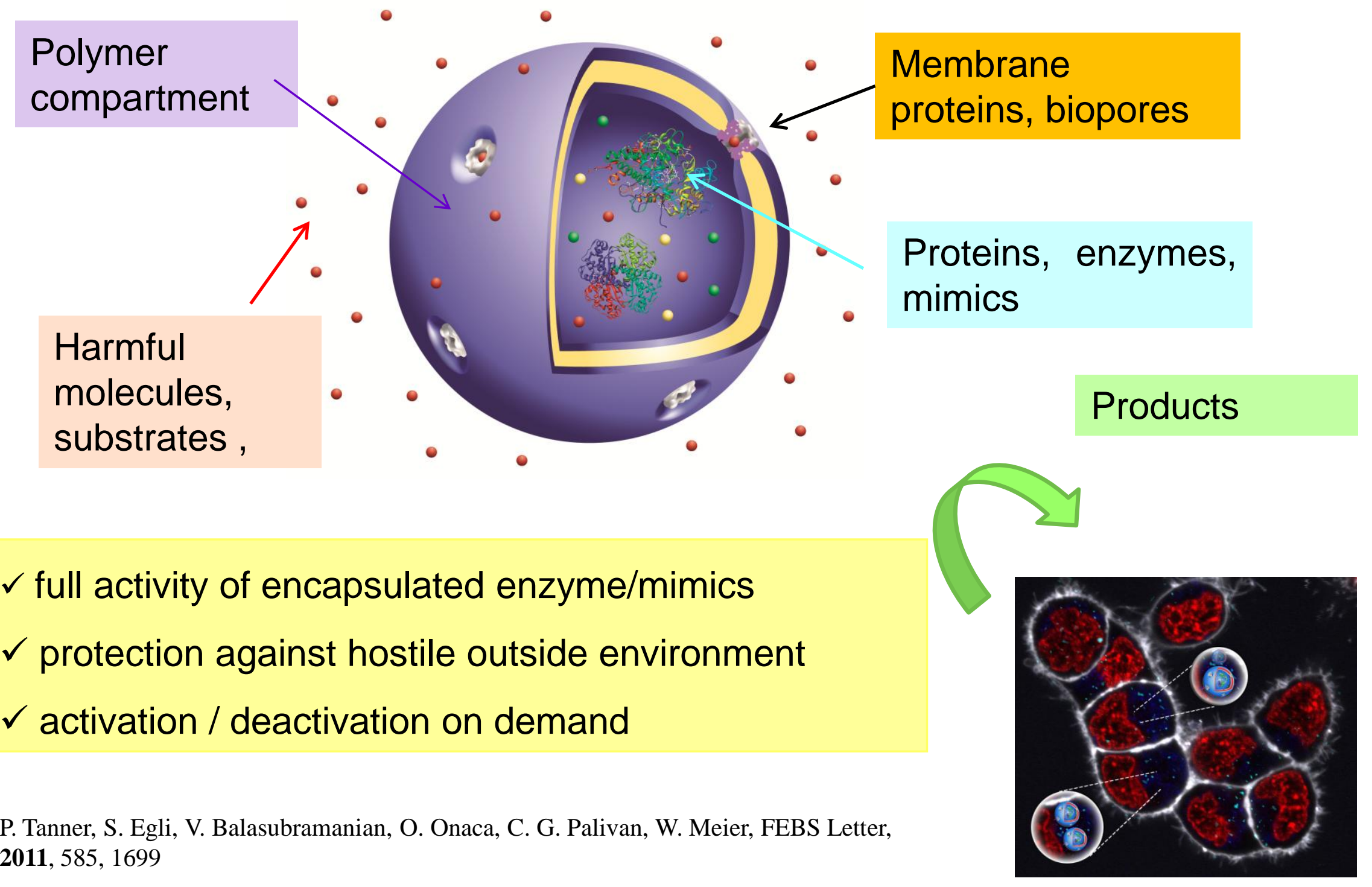




\section{Artificial organelles with triggered activity}
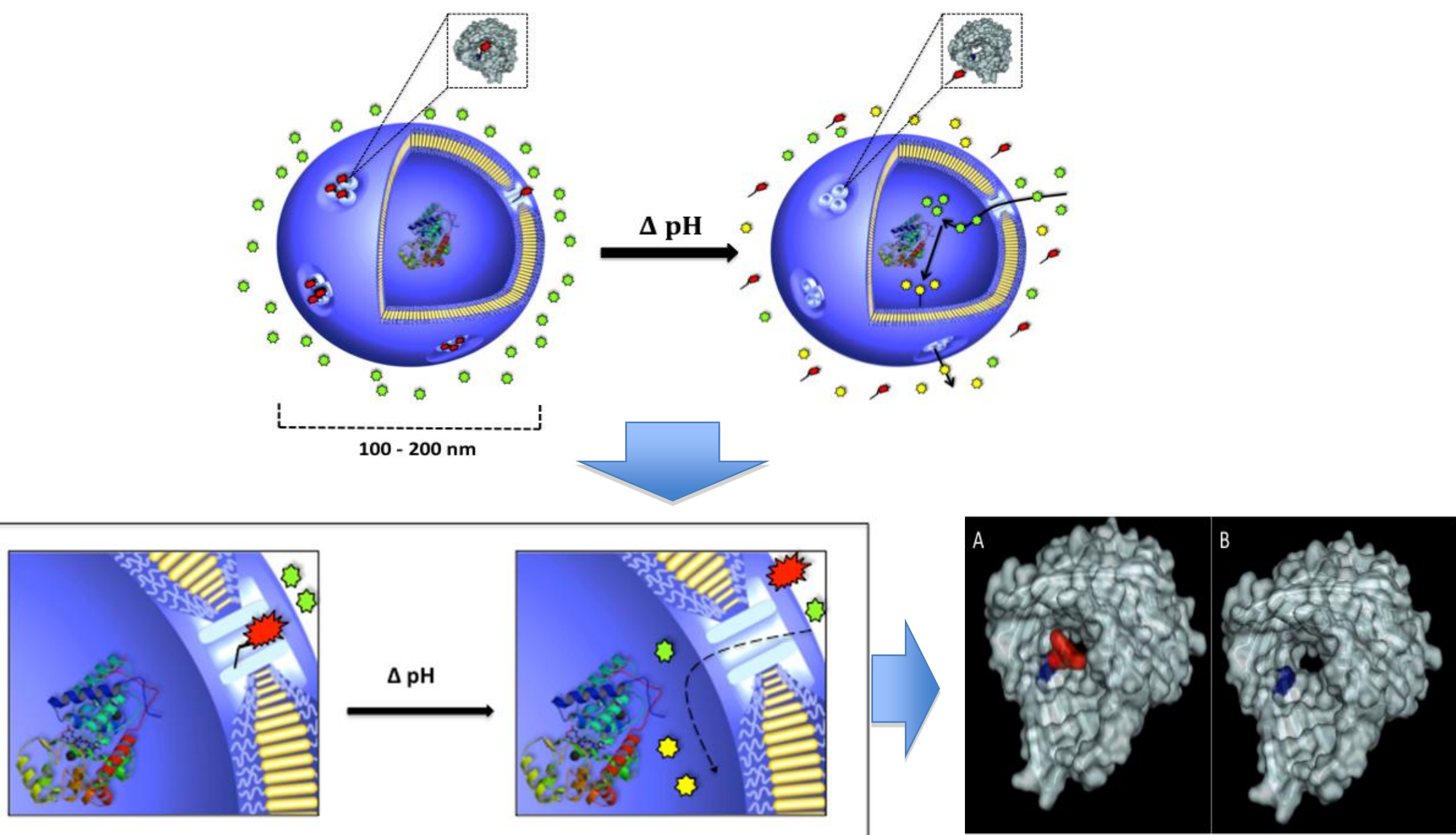

T. Einfalt, R. Goers, A. I.Dinu, A. Najer, M. Spulber, O. Onaca-Fischer, C. G. Palivan, Nano Letters., 2015.

C. Edlinger, T. Einfalt, M. Spulber, A. Car, W. Meier, C. G. Palivan, Nano Letters, 2017. 


\section{Engineering a «protein gate»}

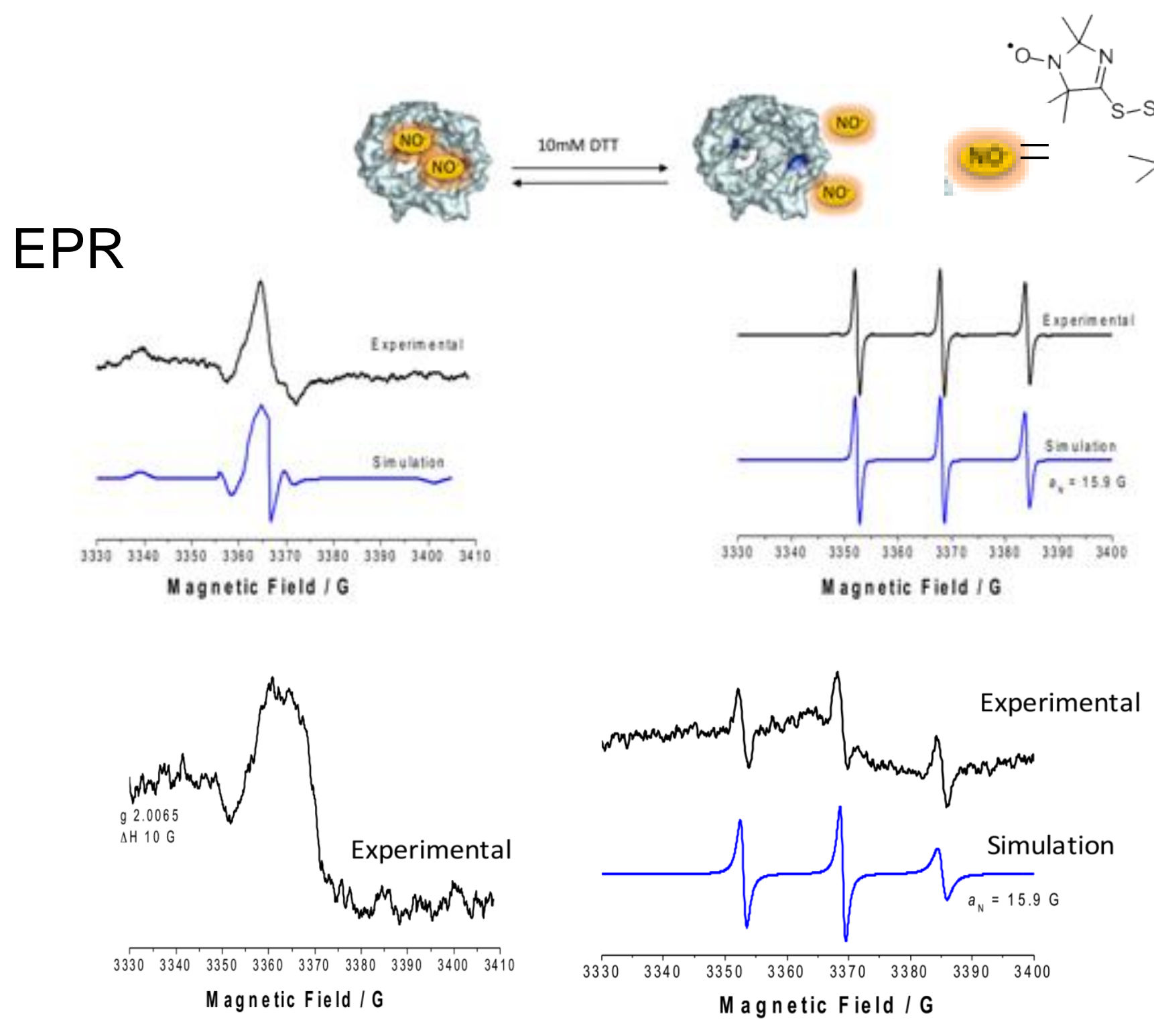




\section{Artificial organelles with protein "gate“}

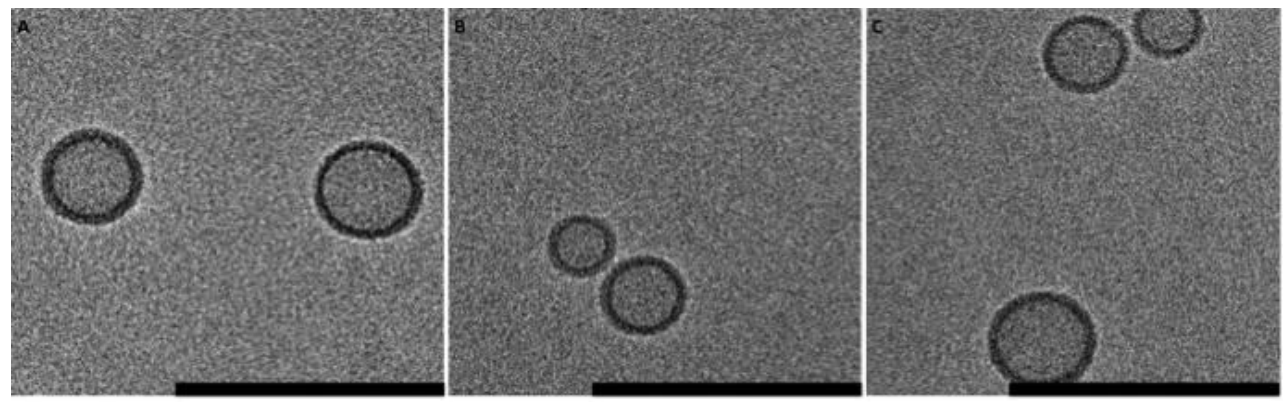

Cryo-TEM: A. Aos without OmpF, B. Aos with reconstituted OmpFWT, and C. Aos with reconstituted OmpF-CA-Cy5. Scale bar $=200$ $\mathrm{nm}$.

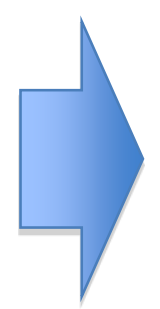

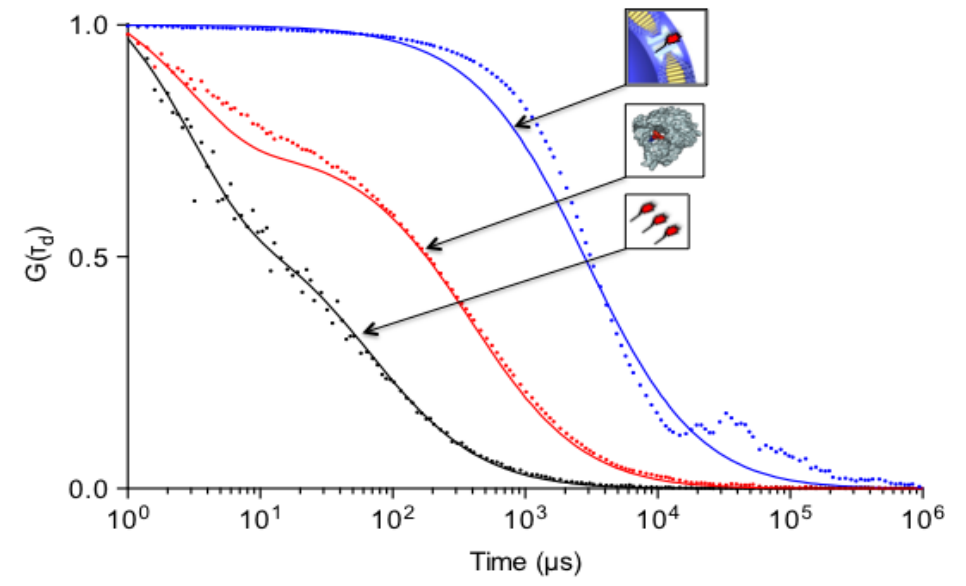

FCS autocorrelation curves of :

- Cy5-hydrazide (Black),

- OmpF-CA-Cy5 (Red)

- OmpF-CA-Cy5 in the membrane of nanocompartments (Blue). 


\section{Artificial organelles with triggered activity}

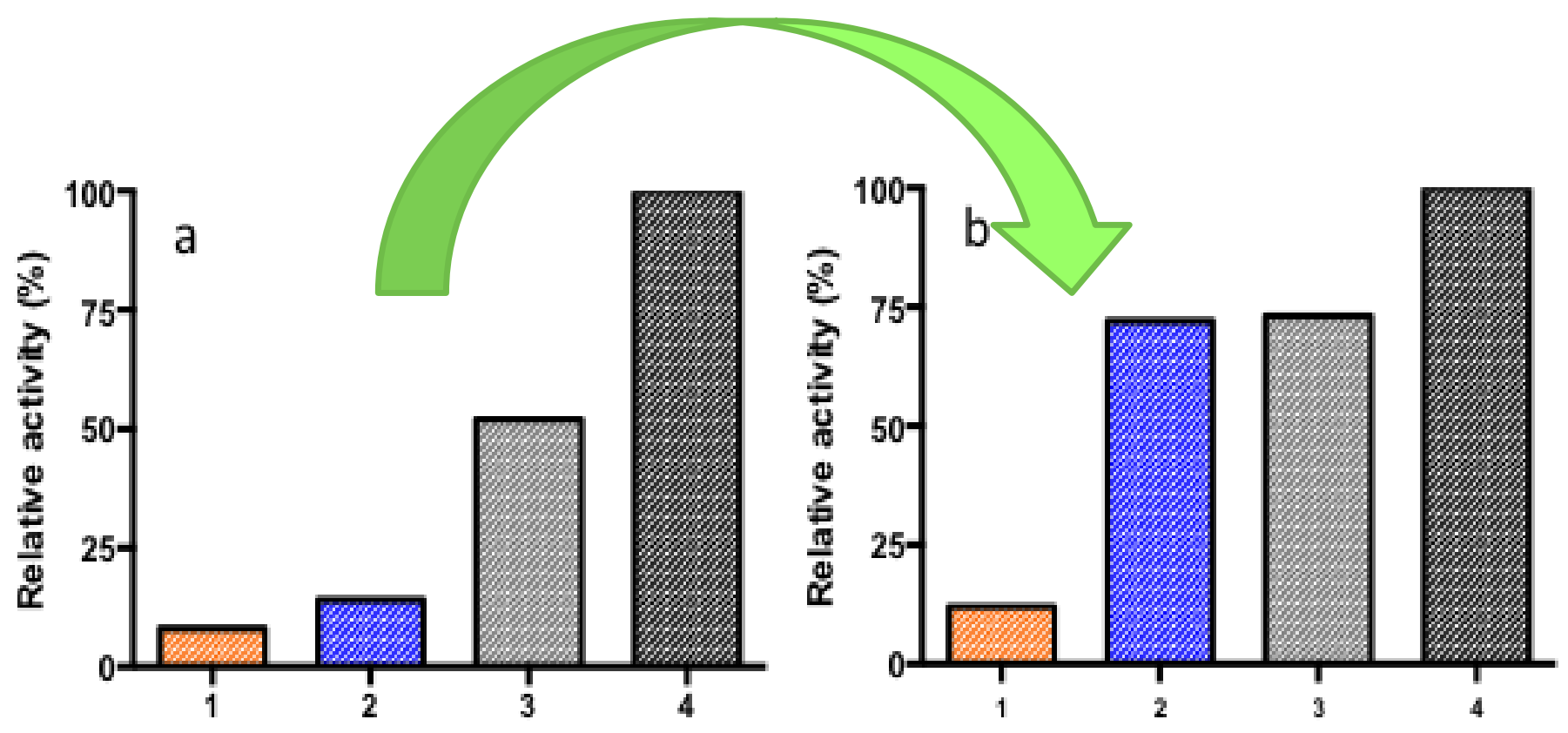

Amplex red conversion kinetics :at $\mathrm{pH}$ 5.5, at time 0 (a)

(1) unpermeabilised nanoreactors (orange)

(2) OmpF-CA-Cy5 (blue)

(3) OmpF-CA (grey),

Amplex red conversion kinetics :at $\mathrm{pH} 5.5$, After 1 hour (B)

(1) unpermeabilised nanoreactors (orange)

(4) Ompf-WT (black)

(2) OmpF-CA-Cy5 (blue)

(3) OmpF-CA (grey),

(4) Ompf-WT (black) 


\section{Triggered artificial organelles in vitro}

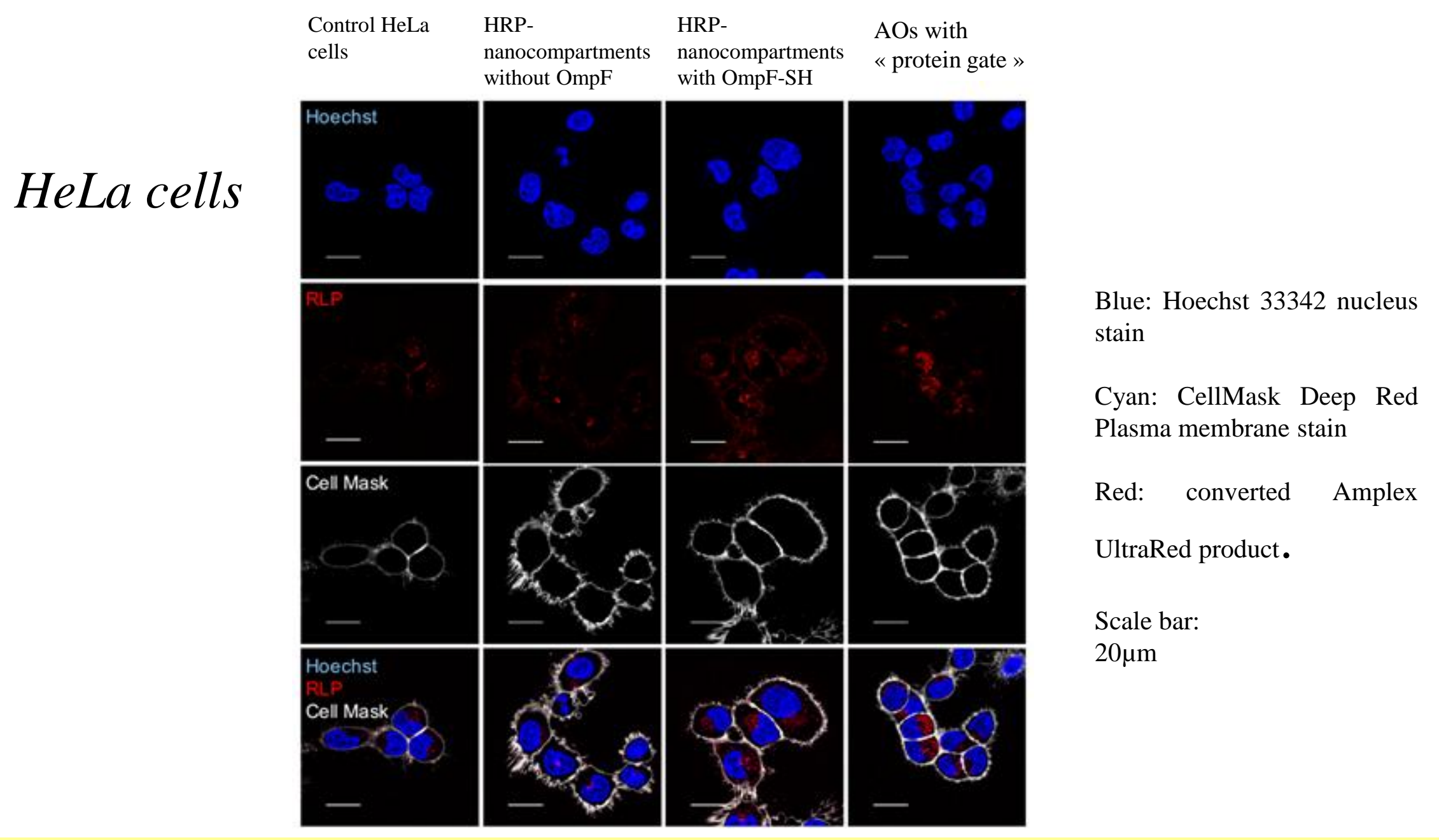

$\checkmark$ Artificial organelles are activated in vitro by reductive changes.

T. Einfalt, D. Witzigmann, C. Edlinger, S. Sieber, R. Goers' A. Najer, M. Spulber O. Ozana-Fischer, J. Huwyler, C. G. Palivan, Nature Comm., 2018. 


\section{Artificial Organelles in vivo}

ZEBRAFISH EMBRYO
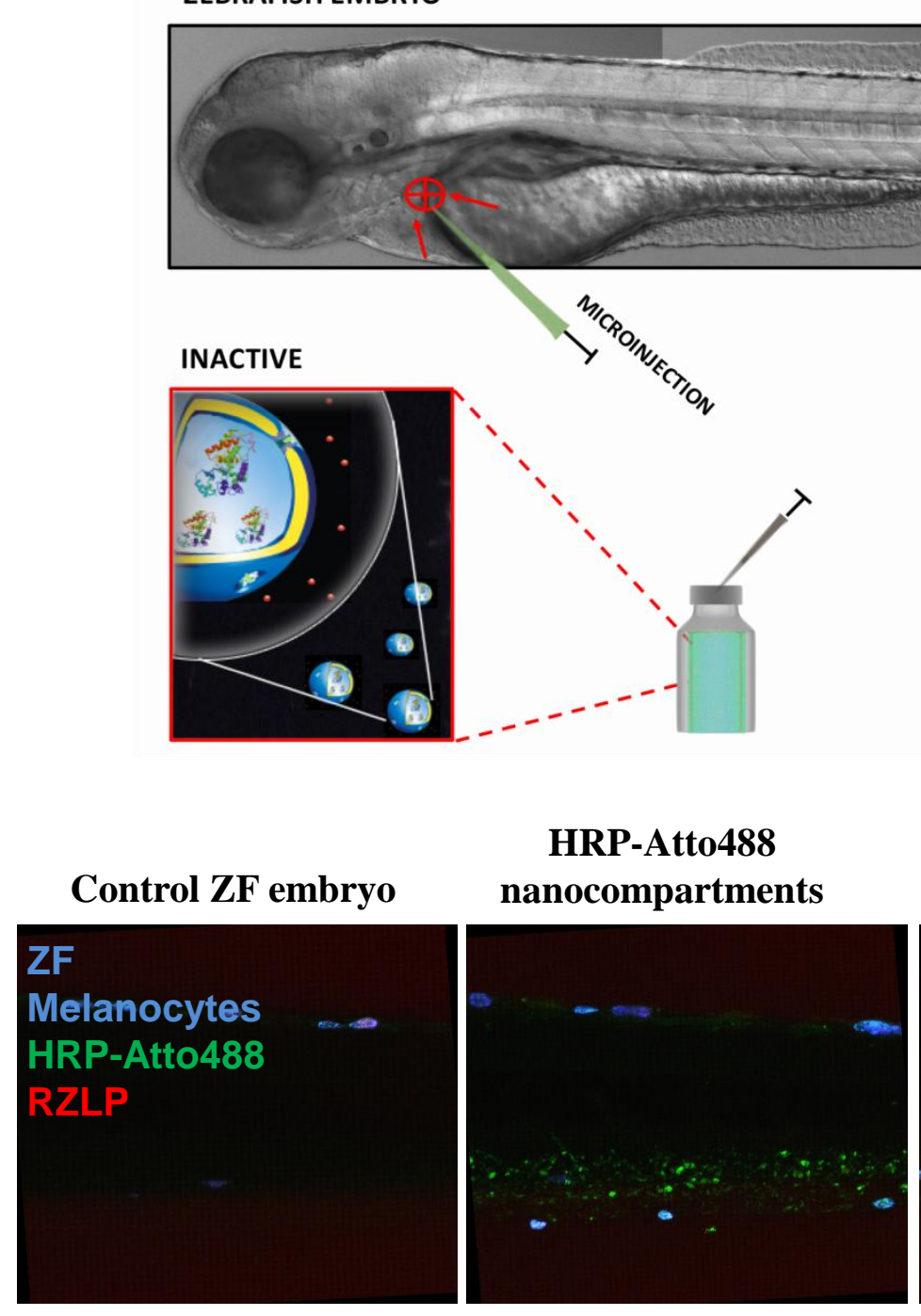

HRP-Atto488nanocompartments with OmpF-SH

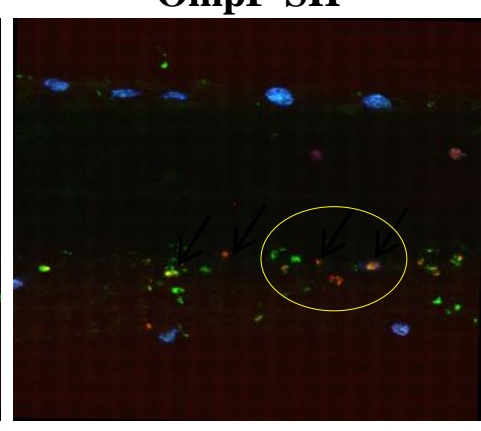

HRP-Atto488 nanocompartments with OmpF-S-S-CF

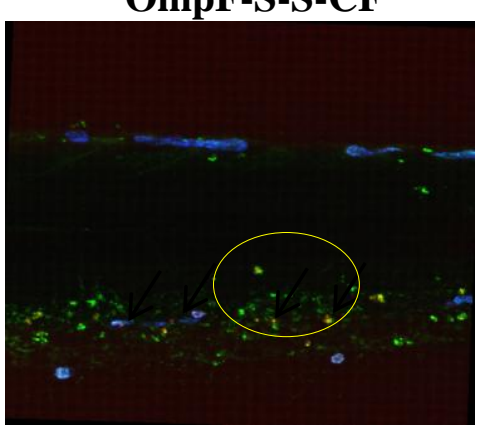

$\checkmark$ Artificial organelles are non-toxic, biocompatible and functional in vivo! 
$>$ Mimics of cells 


\section{Mimics of cellular processes}

\section{A. Stimuli- responsiveness}

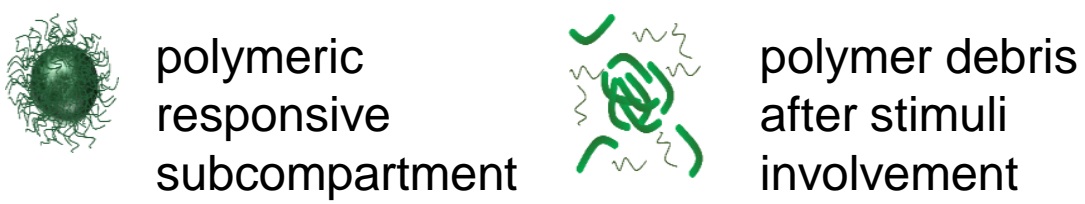

B. Triggered enzyme action by recombination with substrate

C hydrophobic enzyme

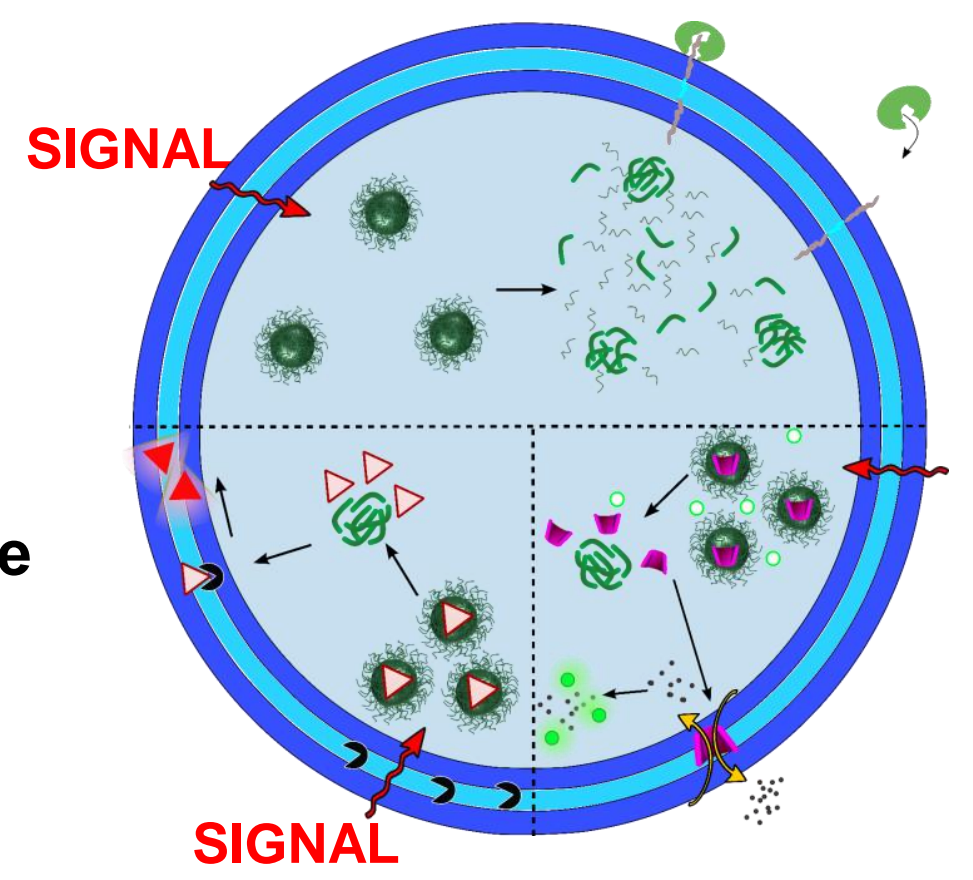

$\triangle$ product

$\triangle$ substrate responsive

subcompartment after stimuli

involvement
SIGNAL

ligand

receptor

C. Triggered ion channel recruitment

reporter compound (non-activated)

reporter compound (activated)

$\gamma$ ion channel

$\therefore$ ions 


\section{Artificial cells- enzymatic reactions}

Concept: Triggered activity of enzymes inside artificial cells by stimuliresponsive recombination of sequestrated substrates with the enzymes

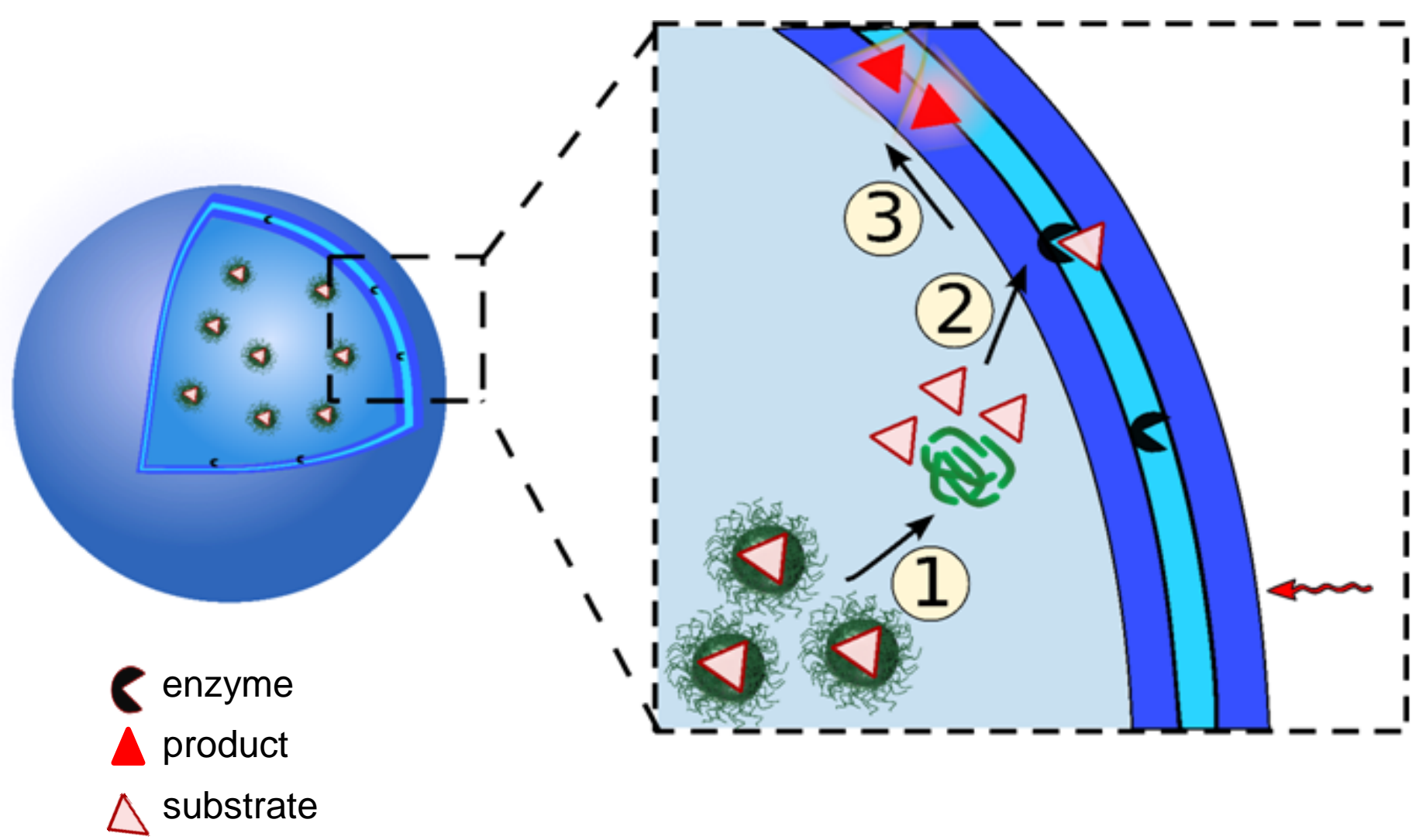

S. Thamboo, A. Najer, A. Belluati, C. von Planta, D. Wu, I. Craciun, W. Meier, C. G. Palivan, Adv. Funct. Mater., 2019, $1904267,1$. A. Beluatti, I. Craciun, C. E. Meyer, S. Rigo, C.G. Palivan, Current Opinion in Biotechnology, 2019, 60C, 53. 


\section{Artificial cells- in situ elements}
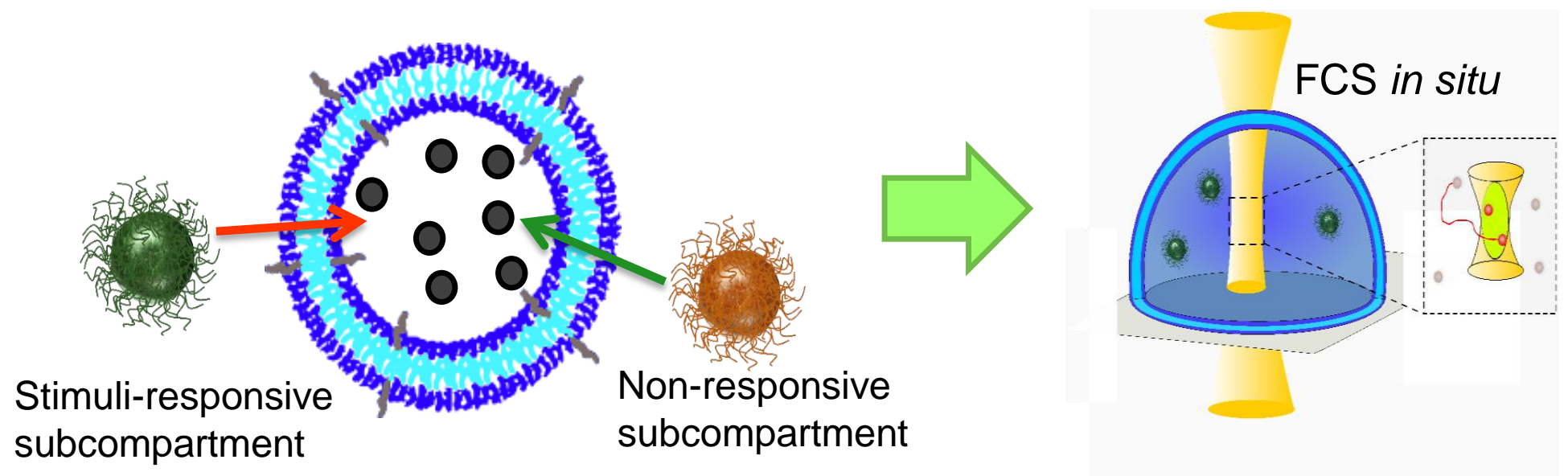

subcompartment subcompartment

FCS autocorrelation curve

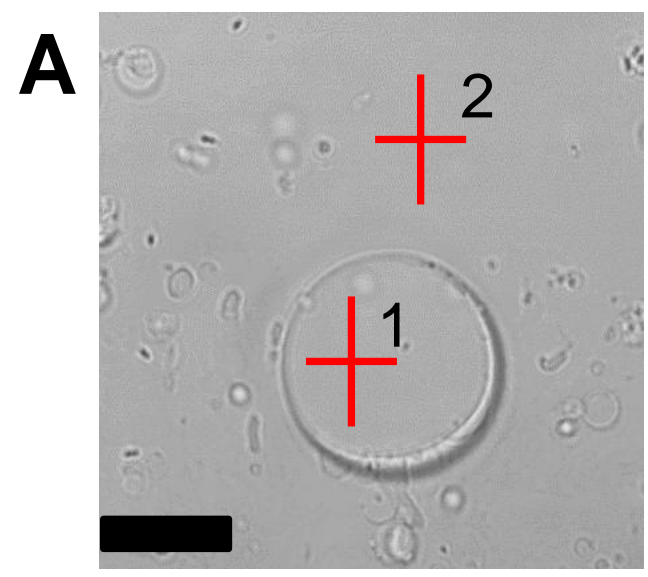

CLSM positioning of the confocal volume
B

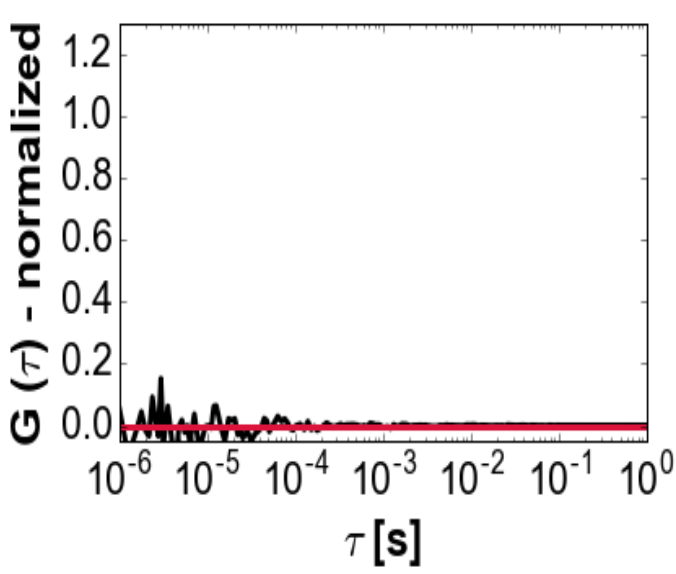

1: Inside GUV

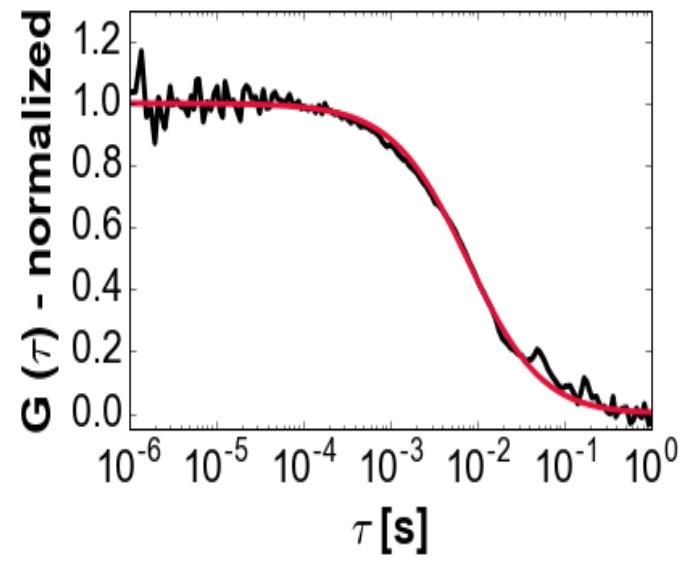

2: Outside GUV 


\section{Encapsulation of stimuli-responsive nanoparticles}
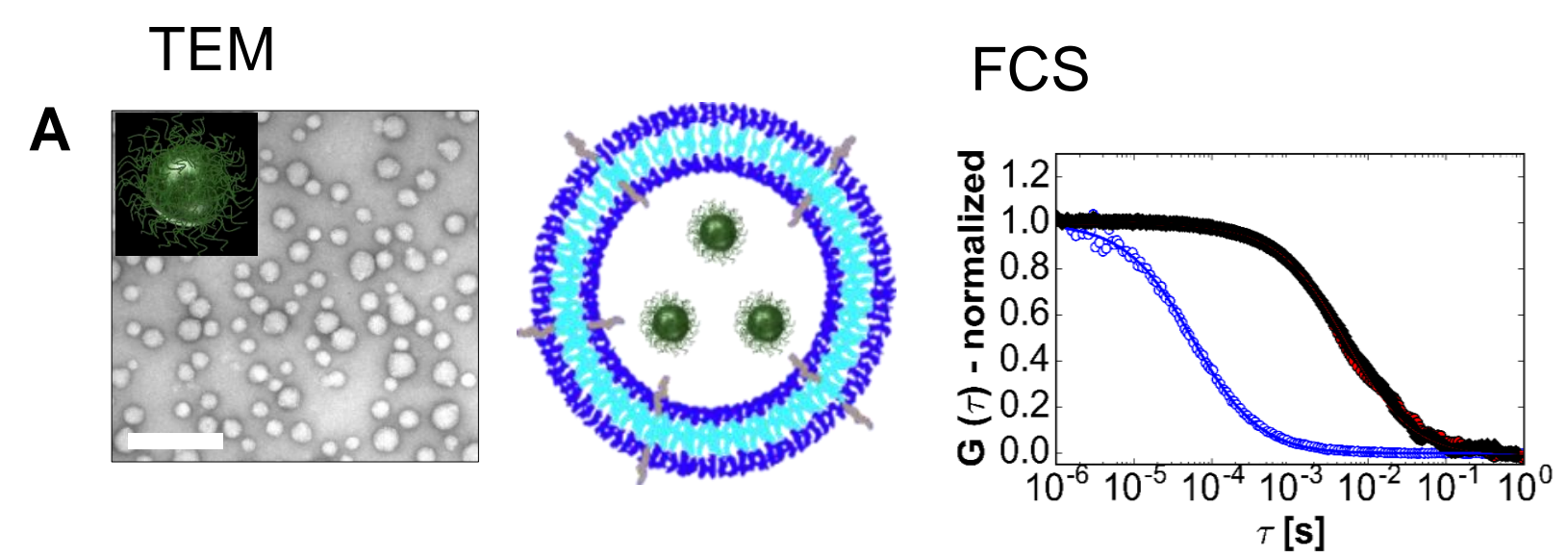

Microscopy

B
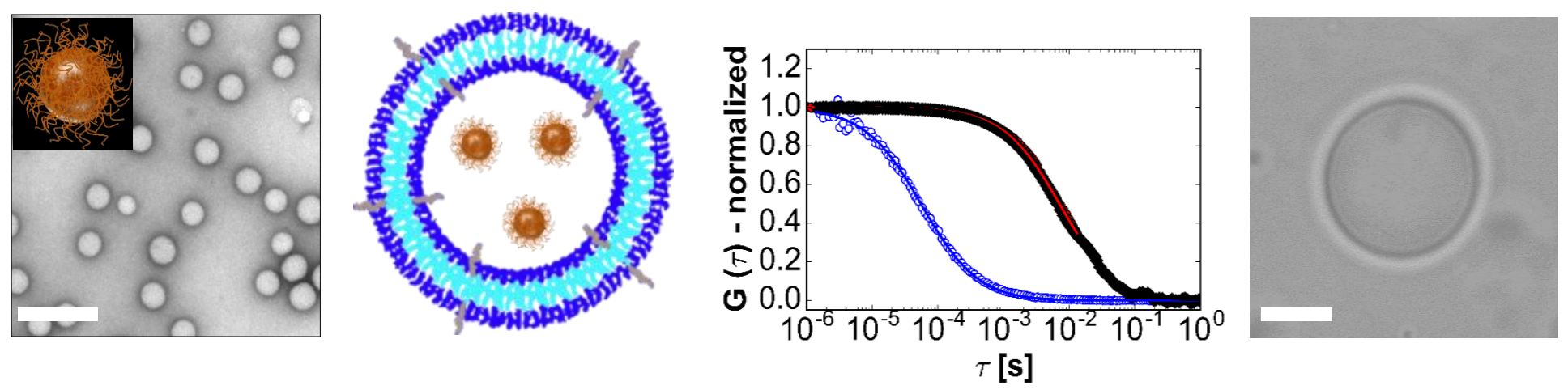

$\checkmark$ Succesful encapsulation of nanopaticles (stimuli-responsive/inert). 


\section{Conclusion and outlook}

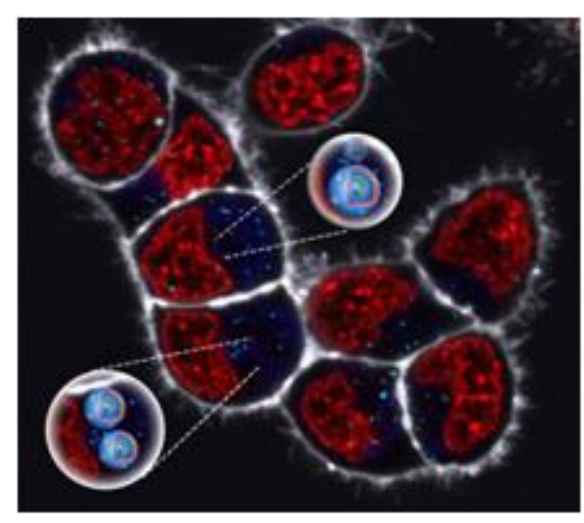

Cellular implants

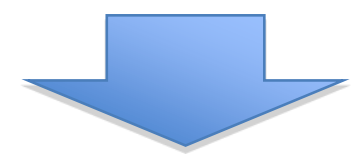

$>$ Active surfaces or membranes with complex functionality

$>$ Molecular factories ...

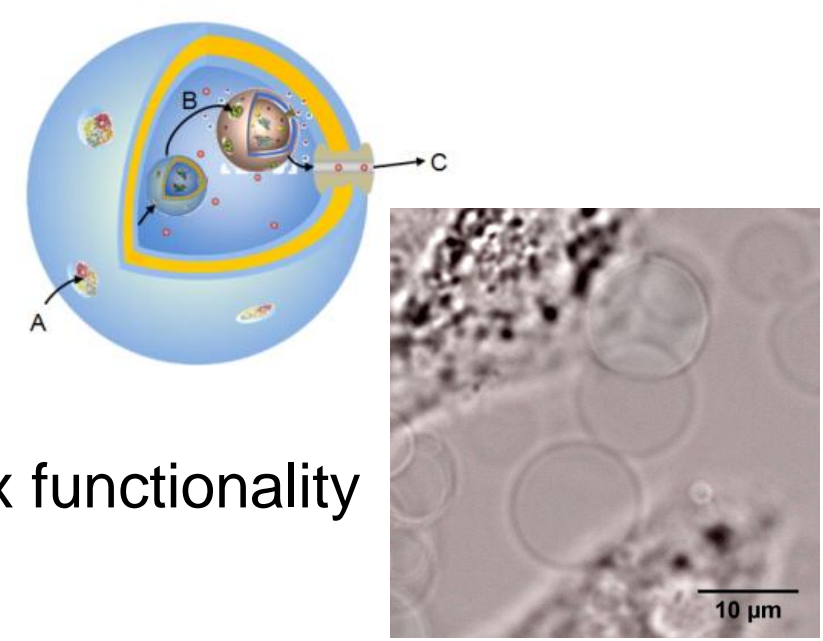




\section{Acknowledgements}

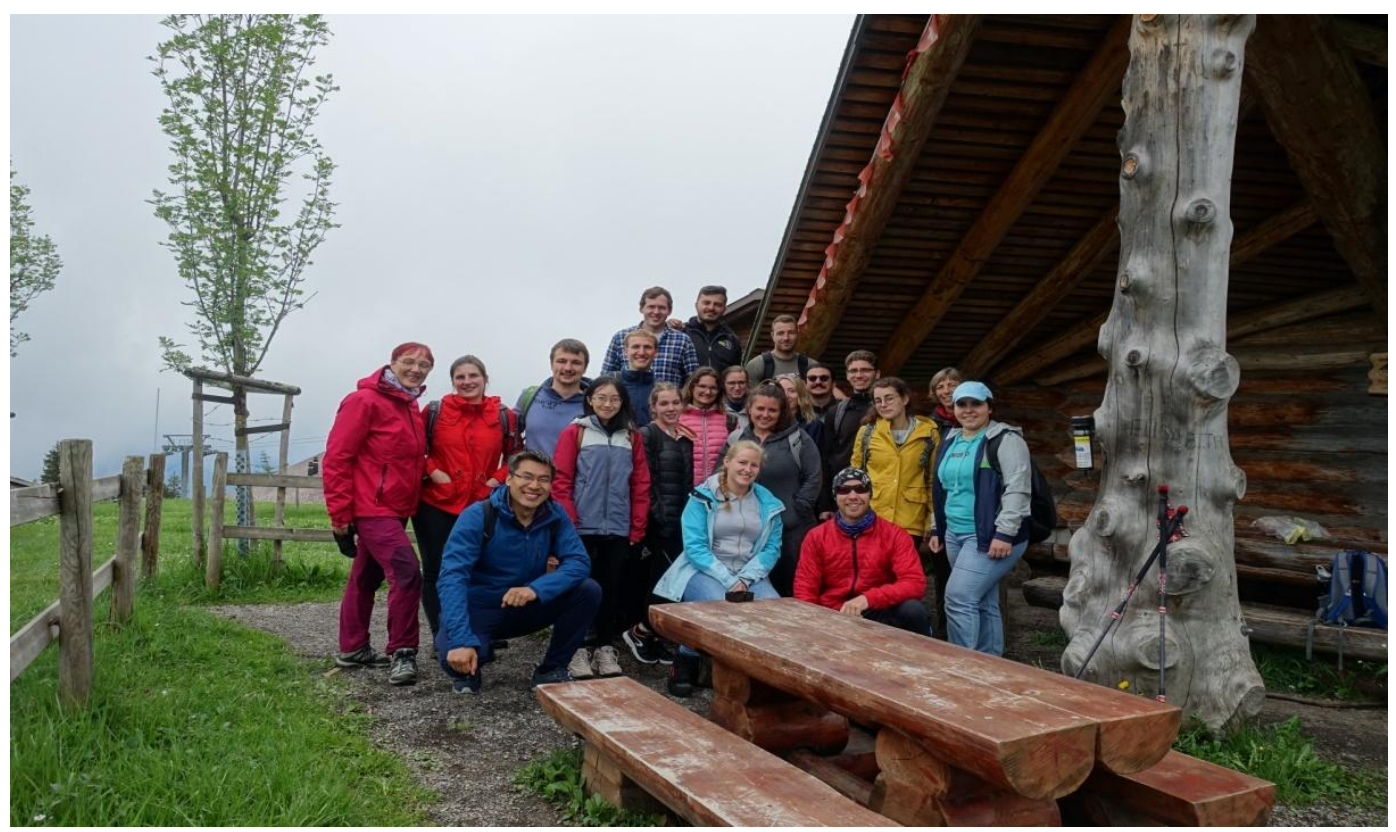

\section{Collaborators:}

Prof. Wolfgang Meier (University of Basel) Prof. Sabine Van Doorslaer (Antwerp University) Prof. Joerg Huwyler (University of Basel) Prof. Abhay Pandit (NUI Gallaway) Prof. Dirk Schneider (Mainz University)
Financial support:

SNSF, NCCR Nanosciences, NCCR-Molecular Systems Engineering Swiss Nanoscience Institute, University of Basel 